\title{
RESTRITIVIDADE DA LEGISLAÇÃO AMBIENTAL EM POSTOS DE COMBUSTÍVEIS
}

\author{
Franciéli Rosa de Franceschi, Vanessa de Matos da Costa, Daniel Benitti Lorenzett, \\ Mauricio Neuhaus, Marivane Vestena Rossato
}

dlorenzett@gmail.com

\section{RESUMO}

O presente estudo pretendeu averiguar a legislação ambiental aplicável aos postos de combustíveis quanto à restritividade de suas disposições, verificando as penalidades associadas ao não cumprimento dessa legislação. Para tanto, utilizou-se a pesquisa bibliográfica qualitativa de cunho exploratório, pois se trata de um assunto pouco explorado. Os resultados demonstraram que a nova Resolução CONAMA prevê penalidades como multas, interdição e até fechamento dos estabelecimentos que não se adequarem a ela, e combinada com a Lei de Crimes Ambientais, as sanções administrativas são acrescidas penas, que responsabilizam criminalmente aqueles que se omitirem das suas obrigações ambientais. Logo, os empreendedores devem estar atentos para o passivo ambiental, o qual pode afetar não somente as finanças, e o valor imobiliário do negócio, como também gerar responsabilidade em todo sistema de sucessão na propriedade da área contaminada, assim, o gerenciamento ambiental eficaz é mais que um cumprimento legal, é também uma questão de sobrevivência do negócio.

Palavras-chave: desenvolvimento sustentável; postos de combustíveis; legislação ambiental

\section{ABSTRACT}

This study sought to ascertain the environmental legislation applicable to the gas stations how much as the limitations of its provisions, noting the penalties associated to no compliance with those laws. To this end, used the bibliographic search of exploratory qualitative, because it is a subject little explored. The new Resolution CONAMA provides penalties such as fines, bans and even closure of establishments which do not adapt of her, and combined with the Environmental Crimes Law, administrative sanctions are increase of penalties, who criminally responsible those who omit their environmental obligations. Entrepreneurs must be aware of the environmental liabilities, which can affect not only the finance and the real estate value of the business, but also incur liability in any system of succession in spot of the contaminated area, thus, the effective environmental management is more than a legal compliance, is also a matter of business survival.

Keywords: sustainable development; fuel stations; environmental law 


\section{INTRODUÇÃO}

O desenvolvimento sustentável é sem sombra de duvidas, fundamental para a continuidade do planeta, essa questão deveria ser encarada como o ponto central para a resolução dos problemas de natureza ambiental presentes no mundo globalizado. A extração dos insumos de forma sustentável seria capaz de suprir as necessidades da geração atual, sem comprometer a capacidade de atender as necessidades das gerações futuras, não esgotando, os recursos naturais existentes no planeta (RIBEIRO, 2006).

Nesse sentido, abordam-se problemas de natureza ambiental, onde as pessoas, tanto físicas quanto jurídicas, despertam recentemente para um modo mais sustentável e ambientalmente correto de viver e se relacionar com o meio ambiente (LORENZETT e ROSSATO, 2010; LORENZETT ${ }^{2}$ et al., 2011). Assim, toma-se a atividade de postos de combustíveis como exemplo dessa relação, pois eles desenvolvem atividades potencialmente poluidoras, tanto para o ar, para as águas como para o solo.

Os postos de combustíveis desenvolvem principalmente atividades de lavagem de veículos, armazenamento e comércio de combustíveis fosseis e bicombustíveis. Esse setor recentemente vem se adaptando e adotando medidas de gestão ambiental para evitar a ocorrência de impactos ao meio ambiente (BARROS, 2006; LORENZETT e ROSSATO, 2010; LORENZETT $^{3}$, 2011; LORENZETT $^{1}$ et al., 2011). As medidas partem dos gestores e do governo através do estabelecimento de legislações ambientais especificas que devem ser aplicadas aos postos de combustíveis. São essas legislações ambientais relacionadas às atividades desenvolvidas em postos de combustíveis que serão objeto de análise no presente estudo.

Desde a Lei Federal no 6.938/81 chamada de Política Nacional do Meio Ambiente a atividade de comércio varejista de combustíveis (postos de gasolina) está submetida à legislação ambiental, sendo regulamentada pelo Decreto Federal no 99.274/90, e também regido pela Resolução do Conselho Nacional do Meio Ambiente (CONAMA) no 237/97 e no 273/00, além de ser citada como atividade sujeita ao licenciamento ambiental, visto que comprovadamente tratase de uma atividade potencialmente poluidora pela armazenagem de combustíveis (produtos perigosos), lavagem de veículos, troca de óleo, geração de resíduos e emissões atmosféricas, somado a isso há o risco de incêndio e acidentes ambientais (SANTOS, 2005; LORENZETT e ROSSATO, 2010; LORENZETT ${ }^{3}$, 2011).

Em virtude das atividades acima mencionadas, tem-se a Lei Federal 9.605/98, que dispõe sobre os Crimes Ambientais. Onde as pessoas jurídicas são responsabilizadas administrativamente, civil e penalmente em caso de infrações cometidas contra o meio ambiente. Fundamentalmente percebe-se que os dispositivos ambientais referem-se a um tema bastante complexo e de ampla abrangência, além do desconhecimento ou não entendimento do conteúdo por parte de muitos empresários, tem-se à visão de que os custos da adequação dos postos à legislação são elevados e com isso a grande maioria opta por não segui - lá, recaindo, assim, na penalidade de ter que pagar elevadas multas, o que culmina no fechamento de muitos postos de combustíveis.

Neste sentido, é possível observar que a preocupação em se aplicar a legislação ambiental nos postos de combustíveis é algo relativamente novo, cabendo aos proprietários o conhecimento dessas normas e leis, sua aplicabilidade e seu cumprimento. Em face disso, surge a seguinte dúvida: a legislação ambiental existente é fortemente restritiva ao ponto de tornar sua adoção, pelos postos de combustíveis, obrigatória?

O objetivo deste trabalho consiste em estudar e interpretar as leis e normas ambientais aplicáveis aos postos de combustíveis quanto à restritividade de suas disposições. O objetivo 
específico é o de verificar as penalidades associadas ao não cumprimento dessas leis por parte dos postos de combustíveis.

\section{LEGISLAÇÃO AMBIENTAL}

Inicialmente é necessário evidenciar a importância do desenvolvimento sustentável, pois ele consiste no ponto chave para as demais aplicabilidades da legislação ambiental. A ECO-92, mais conhecida como a Conferência das Nações Unidas para o Meio Ambiente e o Desenvolvimento (CNUMAD), realizada entre 3 e 14 de junho de 1992 no Rio de Janeiro teve seu objetivo principal de buscar meios de conciliar o desenvolvimento sócio-econômico com a conservação e proteção dos ecossistemas da Terra.

Ficou estabelecido nessa conferência que desenvolvimento sustentável é aquele desenvolvimento que atende às demandas da geração presente, sem comprometer as oportunidades das gerações futuras. Assim, viver de forma sustentável é aceitar o dever de buscar a harmonia com as outras pessoas e o meio ambiente, onde todos têm a obrigação de cuidar bem do Planeta e dos recursos naturais provenientes dele.

A humanidade não pode explorar mais da natureza do que ela pode repor. Ou seja, precisam-se adotar estilos de vida e estratégias de desenvolvimento que respeitem os limites naturais. Isto é possível sem que se rejeitem os benefícios trazidos pela tecnologia moderna, desde que essa também trabalhe dentro destes limites. Este é um plano traçado com uma visão futurista, que busca a sustentabilidade, através não de um retrocesso ao passado, mas sim, de uma inspiração nas origens passadas e na maneira como se exploravam os recursos naturais primitivamente, respeitando a natureza e retirando dela apenas o necessário para manutenção da vida humana, buscando sempre evitar sua degradação (RIBEIRO, 2006).

Para o licenciamento dos postos de combustíveis, deve ser seguido um cronograma que se inicia com o Estudo de Impacto Ambiental (EIA), que é uma avaliação preliminar, necessária para a realização de qualquer obra ou atividade que possam causar lesão ao meio ambiente, e que visa diagnosticar a viabilidade de sua realização, com a finalidade de evitar danos ou pelo menos compensar os problemas ambientais que possam decorrer da obra. Ele é composto por estudos técnicos, científicos, sociais, econômicos e outros que possam aferir o impacto ambiental (TINOCO e KRAEMER, 2004).

Segundo os mesmos autores, após a realização do EIA deve-se fazer o Relatório de Impacto Ambiental (RIMA), detalhando e completando o estudo que será apresentado ao órgão responsável pelo licenciamento. A não realização do EIA/RIMA, quando for necessário, pode acarretar a responsabilidade, do empreendedor ou do órgão licenciador, por eventuais danos ao meio ambiente. Uma vez realizado o EIA/RIMA, o estabelecimento devera dar inicio ao processo de obtenção das três licenças ambientais, indispensáveis para seu funcionamento, que são a licença previa (LP), licença de instalação (LI), e a Licença de operação (LO), respectivamente.

De acordo com Art. 225 da Constituição Federal de 1988, todos têm direito ao meio ambiente equilibrado, bem de uso comum do povo e essencial a sadia qualidade de vida, impondo-se ao poder público e a coletividade o dever de defendê-lo para as presentes e futuras gerações.

Para Astrini (2008), a legislação ambiental é um conjunto de normas jurídicas que se destina a disciplinar a atividade humana, para torná-la compatível com a proteção do meio ambiente. Ela serve, em outras palavras, para proteger a natureza dos nossos excessos. A Lei 
6938/81, em seu Art. 3 dispõe sobre as definições básicas de meio ambiente, degradação da qualidade ambiental, poluição, poluidor e recursos ambientais, Art.3:

Para os fins previstos nesta Lei, entende-se por:

I - meio ambiente, o conjunto de condições, leis, influências e interações de ordem física, química e biológica, que permite, abriga e rege a vida em todas as suas formas;

II - degradação da qualidade ambiental, a alteração adversa das características do meio ambiente;

III - poluição, a degradação da qualidade ambiental resultante de atividades que direta ou indiretamente:

a) prejudiquem a saúde, a segurança e o bem-estar da população;

b) criem condições adversas às atividades sociais e econômicas;

c) afetem desfavoravelmente a biota;

d) afetem as condições estéticas ou sanitárias do meio ambiente;

e) lancem matérias ou energia em desacordo com os padrões ambientais estabelecidos;

IV - poluidor, a pessoa física ou jurídica, de direito público ou privado, responsável, direta ou indiretamente, por atividade causadora de degradação ambiental;

V - recursos ambientais: a atmosfera, as águas interiores, superficiais e subterrâneas, os estuários, o mar territorial, o solo, o subsolo, os elementos da biosfera, a fauna e a flora.

A Lei é bem clara e de fácil entendimento, ao conceituar qualidade ambiental, poluição, poluidor e recursos ambientais e estabelecer relações entre eles. Já o Decreto no 99.274/90, irá apontar as atribuições da Execução da Política Nacional do Meio Ambiente, Art. 1o:

Na execução da Política Nacional do Meio Ambiente cumpre ao Poder Público, nos seus diferentes níveis de governo:

I - manter a fiscalização permanente dos recursos ambientais, visando à compatibilização do desenvolvimento econômico com a proteção do meio ambiente e do equilíbrio ecológico;

II - proteger as áreas representativas de ecossistemas mediante a implantação de unidades de conservação e preservação ecológica;

III - manter, através de órgãos especializados da Administração Pública, o controle permanente das atividades potencial ou efetivamente poluidoras, de modo a compatibilizá-las com os critérios vigentes de proteção ambiental;

IV - incentivar o estudo e a pesquisa de tecnologias para o uso racional e a proteção dos recursos ambientais, utilizando nesse sentido os planos e programas regionais ou setoriais de desenvolvimento industrial e agrícola;

V - implantar, nas áreas críticas de poluição, um sistema permanente de acompanhamento dos índices locais de qualidade ambiental;

$\mathrm{VI}$ - identificar e informar, aos órgãos e entidades do Sistema Nacional do Meio Ambiente, a existência de áreas degradadas ou ameaçadas de degradação, propondo medidas para sua recuperação; e

VII - orientar a educação, em todos os níveis, para a participação ativa do cidadão e da comunidade na defesa do meio ambiente, cuidando para que os currículos escolares das diversas matérias obrigatórias contemplem o estudo da ecologia.

Estabelece, portanto, as incumbências do poder público, no tocante a política nacional do meio ambiente, sua execução e fiscalização. Quanto aos postos de combustíveis, por serem considerados potencialmente poluidores e geradores de acidentes ambientais, pela Resolução CONAMA no 237/97, que considera toda instalação e sistemas de armazenamento de derivados de petróleo e outros combustíveis como empreendimentos de alto risco tanto para a natureza como para a população, devendo, portanto, adequar-se as exigências legais estabelecidas por ela. 
A mesma resolução explicita que os vazamentos de derivados de petróleo e outros combustíveis podem causar contaminação de corpos d'água subterrâneos e superficiais, do solo e do ar. Além disso, levam-se em conta os riscos de incêndio e explosões, decorrentes desses vazamentos, principalmente, pelo fato de que parte desses estabelecimentos localiza-se em áreas densamente povoadas.

O CONAMA, ainda, em sua Resolução $n$ ㅇ 273/00, considera que toda instalação e sistemas de armazenamento de derivados de petróleo e outros combustíveis, configuram-se como empreendimentos potencialmente poluidores e geradores de acidentes ambientais, tomando providencias e regulamentando essas atividades ao exigir delas, para sua operação, as três licenças ambientais, que são a licença previa (LP), licença de instalação (LI) e a Licença de operação (LO).

Assim, o Licenciamento Ambiental constitui-se numa ferramenta de fundamental importância, pois permite ao empreendedor identificar os efeitos ambientais do seu negócio, e de que forma esses efeitos podem ser gerenciados. Com este instrumento busca-se garantir que as medidas preventivas e de controle adotadas nos empreendimentos sejam compatíveis com o desenvolvimento sustentável. O mencionado Licenciamento Ambiental é um Instrumento da Política Nacional do Meio Ambiente, que foi estabelecida pela Lei no 6.938 /81, conforme Art. 9o:

[...] São instrumentos da Política Nacional do Meio Ambiente:

I - o estabelecimento de padrões de qualidade ambiental;

II - o zoneamento ambiental; (Regulamento);

III - a avaliação de impactos ambientais;

IV - o licenciamento e a revisão de atividades efetiva ou potencialmente poluidoras;

V - os incentivos à produção e instalação de equipamentos e a criação ou absorção de tecnologia, voltados para a melhoria da qualidade ambiental;

VI - a criação de reservas e estações ecológicas, áreas de proteção ambiental e as de relevante interesse ecológico, pelo Poder Público Federal, Estadual e Municipal;

VI - a criação de espaços territoriais especialmente protegidos pelo Poder Público federal, estadual e municipal, tais como áreas de proteção ambiental, de relevante interesse ecológico e reservas extrativistas.

A principal função desse instrumento é conciliar o desenvolvimento econômico com a conservação do meio ambiente. A lei estipula em seu Art. 10, que é obrigação do empreendedor buscar o licenciamento ambiental junto ao órgão competente, desde as etapas iniciais do planejamento de seu empreendimento e instalação até a sua efetiva operação. Ainda, conforme a Resolução 237/97 há as seguintes definições sobre licenciamento ambiental e licença ambiental no Art. 10:

[...] Para efeito desta Resolução são adotadas as seguintes definições:

I - Licenciamento Ambiental: Procedimento administrativo pelo qual o órgão ambiental competente licencia a localização, instalação, ampliação e a operação de empreendimentos e atividades utilizadoras de recursos ambientais, consideradas efetiva ou potencialmente poluidoras ou daquelas que, sob qualquer forma, possam causar degradação ambiental, considerando as disposições legais e regulamentares e as normas técnicas aplicáveis ao caso.

II - Licença Ambiental: Ato administrativo pelo qual o órgão ambiental competente, estabelece as condições, restrições e medidas de controle ambiental que deverão ser obedecidas pelo empreendedor, pessoa física ou jurídica, para localizar, instalar, ampliar e operar empreendimentos ou atividades utilizadoras dos recursos ambientais consideradas efetiva ou potencialmente poluidoras ou aquelas que, sob qualquer forma, possam causar degradação ambiental. 
O Licenciamento Ambiental é exigido desde 1997, de acordo com a Resolução CONAMA 237/97, o mesmo é subdividido em três etapas:

- Licença Prévia (LP): Concedida na fase preliminar do planejamento do empreendimento aprovando a sua localização e concepção, atestando a viabilidade ambiental e estabelecendo os requisitos básicos e condicionantes a serem atendidos nas próximas fases de sua instalação;

- Licença de Instalação (LI): Autoriza a instalação do empreendimento com as especificações constantes nos planos, programas e projetos aprovados, incluindo medidas de controle ambiental e demais condicionante da qual constituem motivo dominante; - Licença de Operação (LO): Autoriza a operação da atividade, após a verificação do efetivo cumprimento do que consta das licenças anteriores, com medidas de controle ambiental e condicionantes determinados para operação.

Em caso de não cumprimento da devida legislação ambiental aplicável aos postos de combustíveis, o estabelecimento terá de ser penalizado. Neste sentido, o Art. 8o da Resolução CONAMA 273/00 esclarece:

[...] Em caso de acidentes ou vazamentos que representem situações de perigo ao meio ambiente ou a pessoas, bem como na ocorrência de passivos ambientais, os proprietários, arrendatários ou responsáveis pelo estabelecimento, pelos equipamentos, pelos sistemas e os fornecedores de combustível que abastecem ou abasteceram a unidade, responderão solidariamente, pela adoção de medidas para controle da situação emergencial, e para o saneamento das áreas impactadas, de acordo com as exigências formuladas pelo órgão ambiental licenciador.

A Lei 9.605/98, de crimes ambientais, em seu art. 8 menciona as seguintes penas restritivas de direito, em caso de descumprimento cumprimento da legislação ambiental por parte dos postos de combustíveis:

I - prestação de serviços à comunidade;

II - interdição temporária de direitos;

III - suspensão parcial ou total de atividades;

IV - prestação pecuniária;

$\mathrm{V}$ - recolhimento domiciliar.

No tocante as multas, que se trata de sanção aplicada pelo poder público, tem-se o Decreto 99.274/90, que estabelece em seu Art. 34 que serão impostas multas diárias de 61,70 a 6.170 Bônus do Tesouro Nacional (BTN), proporcionalmente à degradação ambiental causada, nas seguintes infrações:

I - contribuir para que um corpo d'água fique em categoria de qualidade inferior à prevista na classificação oficial;

II - contribuir para que a qualidade do ar ambiental seja inferior ao nível mínimo estabelecido em resolução;

III - emitir ou despejar efluentes ou resíduos sólidos, líquidos ou gasosos causadores de degradação ambiental, em desacordo com o estabelecido em resolução ou licença especial;

IV - exercer atividades potencialmente degradadoras do meio ambiente, sem a licença ambiental legalmente exigível ou em desacordo com a mesma;

V - causar poluição hídrica que torne necessária a interrupção do abastecimento público de água de uma comunidade; 
$\mathrm{VI}$ - causar poluição de qualquer natureza que provoque destruição de plantas cultivadas ou silvestres;

VII - ferir, matar ou capturar, por quaisquer meios, nas Unidades de Conservação, exemplares de espécies consideradas raras da biota regional;

VIII - causar degradação ambiental mediante assoreamento de coleções d'água ou erosão acelerada, nas Unidades de Conservação;

IX - desrespeitar interdições de uso, de passagem e outras estabelecidas administrativamente para a proteção contra a degradação ambiental;

$X$ - impedir ou dificultar a atuação dos agentes credenciados pelo IBAMA, para inspecionar situação de perigo potencial ou examinar a ocorrência de degradação ambiental;

$\mathrm{XI}$ - causar danos ambientais, de qualquer natureza, que provoquem destruição ou outros efeitos desfavoráveis à biota nativa ou às plantas cultivadas e criações de animais;

XII - descumprir resoluções do CONAMA.

No que se refere ao valor das multas, tem-se o Art. 37 do Decreto 99.274/90, que menciona que o valor das multas será graduado de acordo com as seguintes circunstâncias:

I - atenuantes:

a) menor grau de compreensão e escolaridade do infrator;

b) reparação espontânea do dano ou limitação da degradação ambiental causada;

c) comunicação prévia do infrator às autoridades competentes, em relação a perigo iminente de degradação ambiental;

d) colaboração com os agentes encarregados da fiscalização e do controle ambiental;

II - agravantes:

a) reincidência específica;

b) maior extensão da degradação ambiental;

c) dolo, mesmo eventual;

d) ocorrência de efeitos sobre a propriedade alheia;

e) infração ocorrida em zona urbana;

f) danos permanentes à saúde humana;

g) atingir área sob proteção legal;

h) emprego de métodos cruéis na morte ou captura de animais.

\section{MATERIAL E MÉTODOS}

Toda pesquisa utiliza-se de métodos, técnicas e procedimentos para se alcançar o fim pretendido. Para Marconi e Lakatos (2005), o método constitui-se na forma de selecionar técnicas, para se realizar a pesquisa científica. Logo, as técnicas são fruto das decisões do pesquisador, e o modo como as decisões são tomadas depende das regras de decisão do pesquisador. Assim, métodos podem ser entendidos como regras de escolha, e as técnicas como as próprias escolhas.

Quanto à abordagem do problema a pesquisa é considerada qualitativa, uma vez que, para Beuren et al. (2006), a principal diferença entre uma abordagem qualitativa e quantitativa reside no fato de a abordagem qualitativa não empregar um instrumento estatístico no processo de análise do problema. Segundo Ferreira (1988), pode-se definir qualitativo como aquilo que exprimisse ou determina as qualidades do objeto, ao passo que o quantitativo seria relativo à, ou indicativo de quantidade. Essas definições tomadas em conjunto facilitam a compreensão das abordagens, evidenciando que quando qualitativa, ela ira tratar basicamente de fatos ou 
fenômenos mais subjetivos, não quantificáveis, dependendo muitas vezes da percepção do pesquisador.

Quanto aos objetivos, a presente pesquisa foi considerada como pesquisa exploratória, pois de acordo com Gil (2007), este tipo de pesquisa tem como objetivo proporcionar maior familiaridade com o problema, de forma a torná-lo mais explícito. Além de exploratória, a pesquisa também é descritiva, ou seja, além de registrar e analisar os fenômenos estudados busca identificar suas causas. Em relação a esse tipo de pesquisa, Gil (2007), afirma que seu objetivo primordial é a descrição das características de determinada população ou fenômenos ou, o estabelecimento de relações entre as variáveis.

Quanto aos procedimentos o estudo utilizou-se da pesquisa documental para a coleta dos dados, pois segundo Marconi e Lakatos (2005), tal procedimento constitui-se na investigação do tema estudado em documentos, escritos ou não, ou seja, fazendo uso de fontes primárias, como fotos, Leis, jornais e gravações, utilizando-se de fontes que ainda não receberam tratamento analítico.

\section{RESULTADOS E DISCUSSÕES}

Observa-se em função da criação de novas Leis ambientais que normalizam as atividades potencialmente poluidoras, uma crescente preocupação em conciliar o desenvolvimento adequado das empresas com as questões relacionadas ao meio ambiente, de tal forma a promover condições ambientais básicas que não agridam a comunidade e o local onde tais empreendimentos serão instalados. Assim, os esforços feitos para promover a melhoria dos níveis de poluição, seja em termos do ar, água, e solos, tornam-se fundamentais para manutenção da vida humana na terra, mas não só para a vida humana, como também para continuidade de todo o sistema físico, químico e biológico que recobre o planeta. Cabe aos empreendedores, cada vez mais, conscientizar-se das necessidades ambientais locais e responder às suas prioridades e preocupações.

A nova Resolução do CONAMA no 273/00, que "tem força de lei" vem regulamentar a questão ambiental da atividade varejista de comércios de combustíveis, sejam eles fosseis ou não, prevendo penalidades como multas, interdição e até fechamento, e combinada com a Lei de Crimes Ambientais, às sanções administrativas são acrescidas penas, que responsabilizam criminalmente aqueles que se omitirem das suas obrigações ambientais, quando do descumprimento dessa resolução.

A situação pode ser agravada caso ocorram acidentes que coloquem em risco a saúde da população e a integridade dos ecossistemas, arcando o poluidor com indenizações e obrigações civis, independentemente da comprovação de culpa ou não do agente, bastando apenas que se demonstre a relação de causalidade entre a atividade exercida e o dano ocorrido onde a Lei 9.605/98 estabelece multas muitas vezes severas, que podem variar de $R \$ 50,00$ a $R \$ 50$ milhões.

\section{CONSIDERAÇÕES FINAIS}

O meio ambiente é um recurso indispensável à sobrevivência da humanidade, assim como também são indispensáveis certas atividades econômicas. Logo, deve-se buscar efetivar o desenvolvimento sustentável, através do equilíbrio entre ambas. Após a análise da legislação 
pertinente às atividades nocivas ao meio ambiente, desenvolvidas pelos postos de combustíveis, verificou-se que a legislação ambiental existente é fortemente restritiva ao ponto de tornar sua adoção obrigatória aos estabelecimentos desse setor, pois aqueles que não enquadrarem-se aos dispositivos legais e a legislação ambiental vigente serão penalizados, podendo inclusive perder o direito de exercer a atividade. Outro fator muito importante, é que a abertura de novos postos de combustíveis está condicionada a obtenção das três licenças ambientais, e para obtê-las o empreendedor precisa estar adequado a legislação ambiental vigente.

Portanto, os empreendedores devem estar atentos para o passivo ambiental da empresa, o qual pode afetar não somente as finanças, e o valor imobiliário do negócio, como também gerar responsabilidade em todo o sistema de sucessão na propriedade da área contaminada. Logo, o gerenciamento ambiental eficaz do estabelecimento, é mais que um cumprimento legal, é também uma questão de sobrevivência do negócio, e não somente dele, mas também de seus sócios ou até mesmo do proprietário do imóvel onde o empreendimento está inserido, caso seja alugado, uma vez que a responsabilidade é solidária, se estendendo aos bens dos sócios e proprietários do local de instalação das atividades potencialmente poluidoras, em caso de crime ambiental.

Para que se tenha a continuidade desse trabalho, a sugestão para as próximas pesquisas consiste em realizar um estudo mais aprofundado e individualizado, tomando-se por base um posto de combustíveis, onde poderão ser observadas suas atividades, verificadas as interações da empresa com o meio ambiente, e como ela se posiciona em relação à legislação vigente e, ainda, qual tratamento contábil está sendo dado aos eventos ambientais, pois a contabilidade se constitui em uma ferramenta importante, no que diz respeito à divulgação das interações das empresas com o meio ambiente, através da evidenciação desses eventos nos balanços e nas demonstrações.

\section{REFERÊNCIAS}

ASTRINI, M. Projeto de lei pode legalizar destruição de metade da Amazônia. [s.l.]: digital, 2008. Disponível em: <http://colunas.globoamazonia.com/greenpeace/2008/10/>. Acesso em: 20 de Dez. 2009.

BARROS, P.E.O. Diagnostico ambiental para postos de abastecimento de combustíveis: DAPAC. Itajaí: Universidade do Vale do Itajaí, 2006.

BEUREN, I.M. et al. Como elaborar trabalhos monográficos em contabilidade: teoria e prática. 3. ed. São Paulo: Atlas, 2006.

BRASIL. Constituição da república federativa do Brasil. Brasília: Presidência da República, 1988. Disponível em: <http://www.planalto.gov.br/ccivil_03/constituicao/constitui\%C3\%A7ao.htm>. Acesso em: 20 de Set. 2009.

BRASIL. Decreto $\mathbf{n}^{\circ}$ 99.274, de 6 de junho de 1990. Brasília: Presidência da República, 1990. Disponível em: <http://www.planalto.gov.br/CCIVIL/decreto/Antigos/D99274.htm>. Acesso em: 17 de Dez. 2009.

BRASIL. Legislação ordinária. Lei no 9.605, de 12 de fevereiro de 1998: lei de crimes ambientais. Brasília: Presidência da República, 1998. Disponível em: <http://www.planalto.gov.br/ccivil_03/LEIS/L9605.htm>. Acesso em: 19 de Dez. 2009. 
BRASIL. Legislação ordinária. Lei no 6.938, de 31 de agosto de 1981. Brasília: Presidência da República, 1981. Disponível em: <http://www.planalto.gov.br/ccivil_03/Leis/L6938.htm>. Acesso em: 21 de Nov. 2009.

CONAMA. Resoluções: resolução n² 237 de 19 de dezembro de 1997. [s.l.]: CONAMA, 1997. Disponível em: <http://www.mma.gov.br/port/conama/res/res97/res23797.html>. Acesso em: 28 de Out. 2009.

CONAMA. Resoluções: resolução n² 273 de 29 de novembro de 2000. [s.l.]: CONAMA, 2000. Disponível em: <http://www.mma.gov.br/port/conama/res/res00/res27300.html>. Acesso em: 25 de Set. 2009.

CONFERÊNCIA DAS NAÇÕES UNIDAS PARA O MEIO AMBIENTE E O DESENVOLVIMENTO (CNUMAD). ECO-92. Rio de Janeiro, 1992.

FERREIRA, A.B.H. Dicionário Aurélio básico da língua portuguesa. 3. Impressão. Rio de Janeiro: Nova Fronteira, 1988.

GIL, A.C. Como elaborar projetos de pesquisa. 4. ed. São Paulo: Atlas, 2007.

LORENZETT, D.B.; ROSSATO, M.V. A gestão de resíduos em postos de abastecimento de combustíveis. Revista Gestão Industrial, Ponta Grossa, PR, v. 6, n. 2, p. 110-125, 2010. Disponível em: <http://www.pg.utfpr.edu.br/depog/periodicos/index.php/revistagi/article/view/598/479>. Acesso em: 30 de Jun. 2010. doi: 10.3895/S1808-04482010000200006.

LORENZETT ${ }^{1}$, D.B.; NEUHAUS, M.; ROSSATO, M.V.; GODOY, L.P. Gestão de recursos hídricos em postos de combustíveis. Diálogos \& Ciência, v. 9, n. 26, p. 01-11. Salvador, Bahia, 2011. Disponível em: <http://dialogos.ftc.br/index.php?option=com_content\&task=view\&id=273\&ltemid=1>. Acesso em: 28 Jul 2011.

LORENZETT², D.B.; ROSSATO, M.V.; GODOY, L.P. O reconhecimento contábil dos gastos associados às medidas de gestão ambiental no segmento de abastecimento de combustíveis. Revista de Contabilidade e Organizações, v. 5, n. 11, p. 49-68. Ribeirão Preto, SP, 2011 . Disponível em: <http://www.rco.usp.br/index.php/rco/article/view/159/192>. Acesso em: 15 set. 2011.

LORENZETT ${ }^{3}$, D.B.; ROSSATO, M.V.; NEUHAUS, M. Medidas de gestão ambiental adotadas em um posto de abastecimento de combustíveis. Revista Gestão Industrial, v. 7, n. 3. p. 01-21. Ponta Grossa, PR, 2011. Disponível em: <http://www.pg.utfpr.edu.br/depog/periodicos/index.php/revistagi/article/view/635/702>. Acesso em: 20 out. 2011. doi: 10.3895/S1808-04482011000300001.

MARCONI, M.A.; LAKATOS, E.M. Fundamentos de metodologia científica. 6. ed. São Paulo: Atlas, 2005.

RIBEIRO, M.S. Contabilidade ambiental. 2. Tiragem. São Paulo: Saraiva, 2006.

SANTOS, R.J.S. A gestão ambiental em posto revendedor de combustíveis como instrumento de prevenção de passivos ambientais. 2005. 217f. Dissertação (Mestrado em Sistemas de Gestão do Meio Ambiente) - Universidade Federal Fluminense, Niterói, 2005.

TINOCO, J.E.P.; KRAEMER, M.E.P. Contabilidade e gestão ambiental. São Paulo: Atlas, 2004. 